\title{
IN VIVO HEPATOPROTECTIVE ACTIVITY OF CASSIA AURICULATA POLYMER NANOSPHERES CONTAINING SILYMARIN
}

\section{A. KEERTHI SAGAR ${ }^{1 *}$, G. DEVALA RAO ${ }^{2}$}

${ }^{1}$ Department of Pharmaceutical Sciences, Acharya Nagarjuna University, Guntur, Andhra Pradesh, India. ${ }^{2}$ Department of Pharmaceutical Sciences, KVSR Siddhartha Institute of Pharmaceutical Sciences, Vijayawada, Andhra Pradesh, India. Email: keerthisagar2015avula@gmail.com

Received: 31 May 2016, Revised and Accepted: 10 June 2016

\section{ABSTRACT}

Objective: Hepatoprotective activity of herbal drugs has an importance in the treatment of hepatic disorders, but pharmaceutically engineered products are not evolved properly to cure the liver disorders properly based on the demand and also route, target the appropriate site of action.

Methods: In our present work, we have been developed a new formulation that possesses a unique nature and site specificity for targeting the disease state. Here, we examined hepatoprotective activity of Cassia auriculata polymer nanospheres containing silymarin against carbon tetrachlorideinduced hepatotoxicity in rats using at $50 \mathrm{mg} / \mathrm{kg}$ and $100 \mathrm{mg} / \mathrm{kg}$ body weight dose levels, and we have been observed that enzyme activities of serum glutamate oxaloacetate transaminase, serum glutamate pyruvate transaminase, alkaline phosphate, total protein, albumin, globulin, total cholesterol high-density lipoprotein (HDL), glutathione (GSH), and total bilirubin were analyzed.

Results: $C$. auriculata polymer nanospheres and silymarin produced significant $(\mathrm{p}<0.001)$ hepatoprotective effect by decreasing the activity of serum enzymes, bilirubin, total cholesterol, and increased levels of HDL, total protein, albumin, globulin, and tissue GSH.

Conclusion: From these results, it was concluded that of $C$. auriculata polymer nanospheres would protect the liver cells from carbon tetrachloride from liver diseases.

Keywords: Hepatoprotective activity, Silymarin, Cassia auriculata, Nanospheres.

\section{INTRODUCTION}

The Greek word, hepar is evolved and it starts as hepato or hepatic in pharmacy or medical terms, which means liver. The liver plays a pivotal role in metabolism, storage, and secretion of enzymes and also stored food[1]. It is referred as great synthetic/chemical factory of the body, which regulates, synthesizes, store, and secret many important enzymes, proteins, nutrients, and it can metabolize the consumed products either form food, chemicals, or pharmaceutical dosage forms, which enter into the liver via systemic circulation and it will eliminate for the body as toxic wastes. The bile produced and secreted form the liver plays very important role in the digestion of food and also fatty acids into cholesterol. The risk of the liver intoxication has recently increased by the higher exposure to environmental toxins, pesticides, and the frequent dosage of pharmaceutical products of a variety of classes[2].

Phytochemical and pharmacological investigation have been done extensively and well established. Phytomedicines show impressive invitro activity but less in-vivo efficacy due to their poor water solubility, lipophilicity, and inappropriate molecular size resulting in poor absorption and hence poor systemic availability. A better understanding of the biopharmaceutics and pharmacokinetics of phytomedicine can also help in designing rational dosage regimens [3]

Nanotechnology is on the threshold of providing a host of new materials and approaches in revolutionizing the medical and pharmaceutical field. Several areas of medical care are already profiting from the advantage of nanotechnology [4]

The use of nanotechnology for treatment, identification, monitoring, and managing biological systems have recently been referred to as nanomedicine. In the herbal formulation research, incorporating the nano-based formulation has a great number of advantages for phytomedicine, including improvement of solubility and bioavailability, safeguard from toxicity, enhancement of pharmacological activity, improvement of stability, increase in tissue macrophages distribution, sustained delivery, and protection from physical and chemical degradation [5].

\section{Aim and objective}

Our objective of the study is to investigate the hepatoprotective activity of Cassia auriculata polymer nanospheres against carbon tetrachloride induced hepatotoxicity in Wistar rats.

\section{METHODS}

Carbon tetrachloride (fine chemicals) and silymarin (Sigma - Aldrich) were used in our study. All other chemicals and reagents used were of analytical grade.

\section{Collection of plant material}

The seeds of the plant were collected from the foothill of Tirupati, Andhra Pradesh, in the month of March 2013. The collected plant was identified and authenticated by a botanist. The seeds were shade dried at room temperature for 10 days and coarse powdered and passed through sieve No. 60 .

Isolation of mucilage for aqueous extract

The mucoadhesive from $C$. auriculata Linn was prepared by the following method.

Extraction and isolation involves seeds were size reduced to coarse powder. $100 \mathrm{~g}$ of this coarse powder was taken in $1000 \mathrm{~mL}$ beaker with water of $500 \mathrm{~mL}$ and boiled for 45 minutes- $1 \mathrm{hr}$ and filter using muslin cloth to obtain gum mucilage. This mucilage was diluted with $500 \mathrm{~mL}$ of water to obtain polymerization and finally was mixed with $500 \mathrm{~mL}$ of ethanol. The precipitates again dissolved in water, filtered to remove any debris and recrystallized using ethanol. The precipitate obtained after filtration were dried in hot air oven at $45^{\circ} \mathrm{C}$ for $12 \mathrm{hrs}$ and size reduced to get powdered gum of \#80 sieve fraction. 
Preparation of nanospheres using $C$. auriculata polymer

C. auriculata polymer nanospheres encapsulated with silymarin, which is a hepatoprotective drug, were prepared by emulsion polymerization method in continuous aqueous phase. C. auriculata polymer extracted with ethanol has labeled as CAE, and it was dissolved with dichloromethane. Silymarin was dissolved in $1 \%$ solution of Tween 80 The drug solution and polymer solution were emulsified at $15^{\circ} \mathrm{C}$ using magnetic stirrer for 10 minutes.

This solution was sonicated for 20 minutes at $15^{\circ} \mathrm{C}$. The nanoparticles of silymarin were separated by fractional centrifugation using a cooling centrifuge and redispersed in phosphate buffer saline $\mathrm{pH}$ 7.2. Six batches of nanospheres were prepared with varied drug polymer ratio and emulsifying agent ratio (Table 1).

In vitro release profile of $C$. auriculata polymer nanospheres containing silymarin

About $100 \mathrm{mg}$ equivalent weight of the silymarin taken in a dialysis tube and placed in $250 \mathrm{~mL}$ of phosphate buffer $\mathrm{pH}$ 7.4. The medium was stirred using the magnetic stirrer, and the temperature was maintained at $37 \pm 0.5^{\circ} \mathrm{C}$. Periodically, $1 \mathrm{~mL}$ of the samples was withdrawn and diluted to $10 \mathrm{~mL}$ using phosphate buffer. After each with drawal, the same quantity of the fresh medium was replaced immediately. Then, the samples were assayed spectrophotometrically, systronics UV spectrophotometer 119 at $288 \mathrm{~nm}$ using, medium is blank. The release was compared with marketed silymarin conventional tablets, silybon 140 .

\section{Standard graph of silymarin}

About $100 \mathrm{mg}$ of silymarin was dissolved with $100 \mathrm{~mL}$ of phosphate buffer $\mathrm{pH} 7.4$ to produce the concentration of $1 \mathrm{mg} / \mathrm{ml}$. From that stock solution, $1 \mathrm{~mL}$ of the solution was taken, and it was further diluted to produce the concentration of $10 \mu \mathrm{g} / \mathrm{mL}$. Form that $1-10 \mathrm{~mL}$ of the solution was withdrawn and diluted to $10 \mathrm{~mL}$ with phosphate buffer in a $10 \mathrm{~mL}$ standard flask to produce $1-10 \mu \mathrm{g} / \mathrm{mL}$ concentration. Then, these samples were assayed spectrophotometrically, systronics UV spectrophotometer 119 , at $288 \mathrm{~nm}$, using the corresponding medium as blank.

Selection of CAE nanospheres RF1 for hepatoprotective activity With the about in vitro dissolution studies and release pattern of formulations RF1 and RF2. We have been selected RF1 formulation for in vivo hepatoprotective activity in Swiss Albino Rats because RF1 was shown better release characteristics than RF2 formulation.

Table 1: Formulation of silymarin nanospheres. CAE: Cassia auriculata ethanol extracted polymer

\begin{tabular}{llll}
\hline Formulation & Drug & Polymer & Tween 80 \\
\hline RF1 & 1 & 1 CAE & 1 \\
RF2 & 2 & 1 CAE & 2 \\
\hline
\end{tabular}

C. auriculata Cassia auriculata
Acute toxicity studies for $C$. auriculata polymer

Acute toxicity studies were performed according to Organisation for Economic Cooperation and Development 423 guidelines. Male Swiss mice weighing $30 \pm 5$ selected by technique were used. The animals were fasted for $3 \mathrm{hrs}$ with free access to water only; $C$. auriculata polymer was administered orally at a dose of $5 \mathrm{mg} / \mathrm{kg}$ initially. Mortality was observed for 2 days. If mortality was observed in two of three animals, then the dose administered was considered as toxic dose. However, it was found to be safe and no mortality was observed, the procedure was repeated for further higher dose such as 50,100, 200 up to $3500 \mathrm{mg} / \mathrm{kg}$ body weight (BW). The animals were observed for toxic symptoms such as behavioral changes, locomotion changes, locomotion convulsion, and mortality for $24 \mathrm{hrs}$. It was found to be safe as per $\mathrm{LD}_{50}$, and the polymer has allowed for further pharmacological investigations. $1 / 5$ and $1 / 10$ dose of the $C$. auriculata polymer is advisable. It is used as excipient rather than the drug form[6].

Two maximal doses of $C$. auriculata nanospheres of formulation RF1 of 50 and $100 \mathrm{mg} / \mathrm{kg} \mathrm{BW}$ was calculated and continued further investigations.

\section{Hepatoprotective activity}

Animals

- Species: Albino Wistar rats

- Weight/size: Rats, $200 \pm 20 \mathrm{~g}$

- Gender: Male

- Number to be used: 6 animals in each group

- Healthy male Wistar rats weighing $(200 \pm 20)$ maintained under controlled temperature at $23^{\circ} \mathrm{C} \pm 2^{\circ} \mathrm{C}$ and a $12 \mathrm{hrs}$ light - $12 \mathrm{hrs}$ dark period will be employed for the experimentation. Animals used for the study were supplied by the Smt. Sarojini Ramulamma College of Pharmacy, Animal House. Animals were housed in large spacious polypropylene cages on clean paddy husk bedding during the experimental period. The study was conducted after obtaining clearance from the Institutional Animal Ethics Committee (Reg. No. 1406/PO/a/12/CPCSEA) of Smt. Sarojini Ramulamma College of Pharmacy, Mahabub Nagar [7].

Number of animals required

Total number of animals required

- Number of animals for acute toxicity $=18$

- Number of animals in each group $=6$

- Number of groups $=5$

Total number of animals required $=(6 \times 5)=30+18=48$

\section{Dose}

C. auriculata polymer nanospheres containing silymarin, the dose is $50 \mathrm{mg} / \mathrm{kg} \mathrm{BW}$ and $100 \mathrm{mg} / \mathrm{kg} \mathrm{BW}$ are taken for two different groups, i.e. Groups IV and V, respectively.

Table 2: In vivo hepatoprotective activity of nanospheres containing silymarin with Cassia auriculata polymer

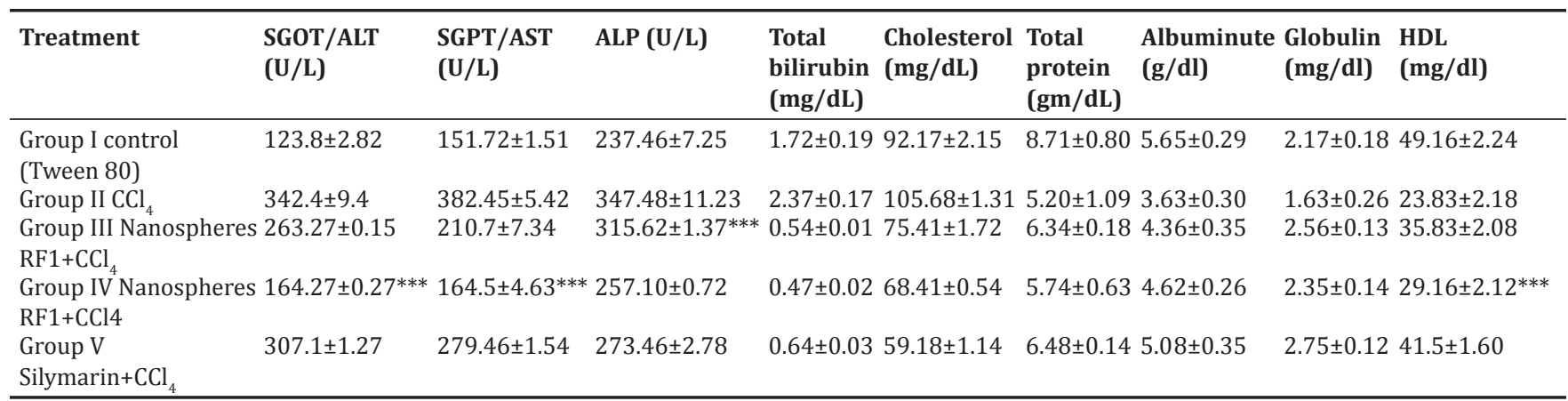

The $\mathrm{p}<0.001,\left({ }^{* * *} \mathrm{p}<0.001\right),{ }^{* * *}$ indicates extremely significant. SGOT: Serum glutamate oxaloacetate transaminase, SGPT: Serum glutamate pyruvate transaminase, ALP: Alkaline phosphate, HDL: High-density lipoprotein 


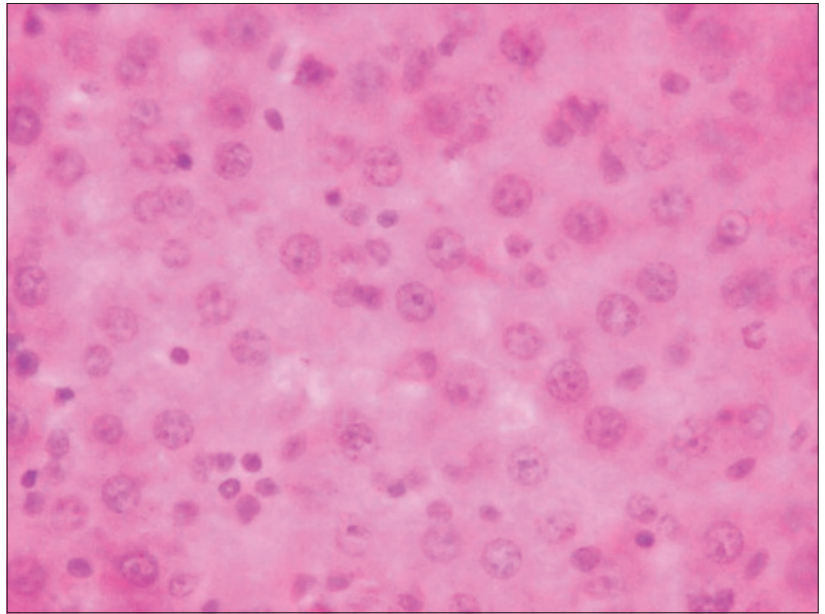

Fig. 1: Group I: Control

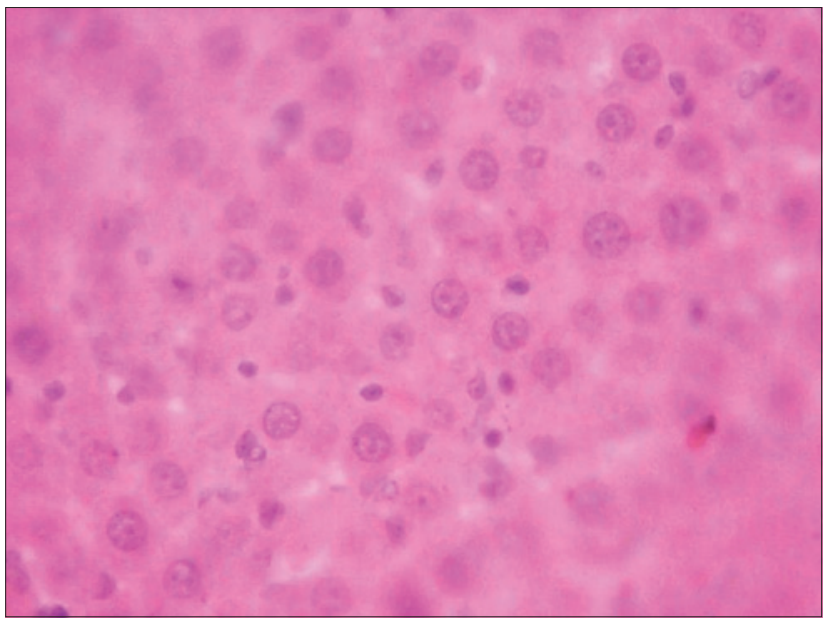

Fig. 2: Group II: Negative control- $\mathrm{CCl}_{4}$ treated

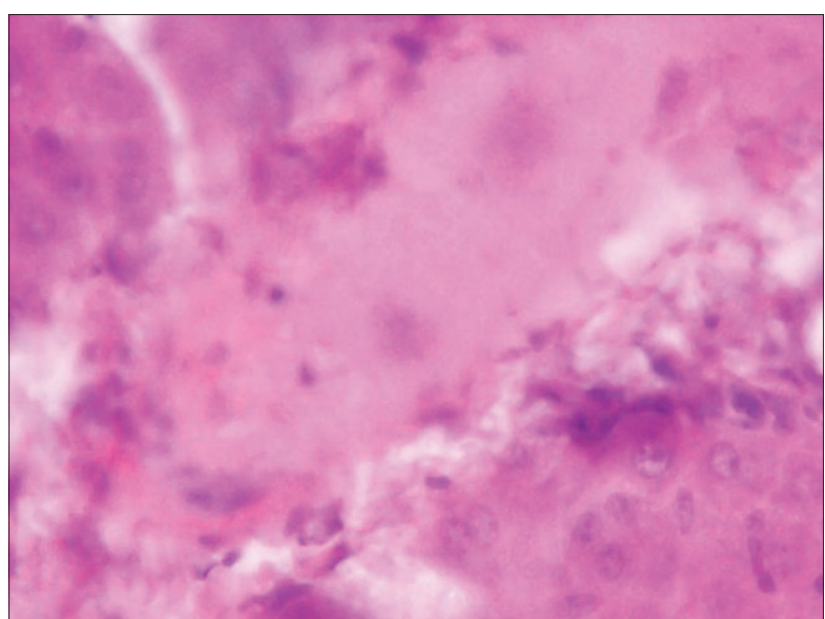

Fig. 3: Group III: Silymarin (50 mg/kg body weight $)+\mathrm{CCl}_{4}$ treated

\section{Experimental design}

Rats were divided into 5 groups, and each group consists of six animals. Group 1: It was served as control and received vehicle 2\% Tween 80 p.o $2 \mathrm{~mL} / \mathrm{kg}$ BW for 7 days.

Group 2: It was served as negative control and received 2\% Tween 80 p.o $2 \mathrm{~mL} / \mathrm{kg}$ BW for 7 days.

Group 3: It was a standard group, received silymarin $25 \mathrm{mg} / \mathrm{kg}$ BW for 7 days p.o.

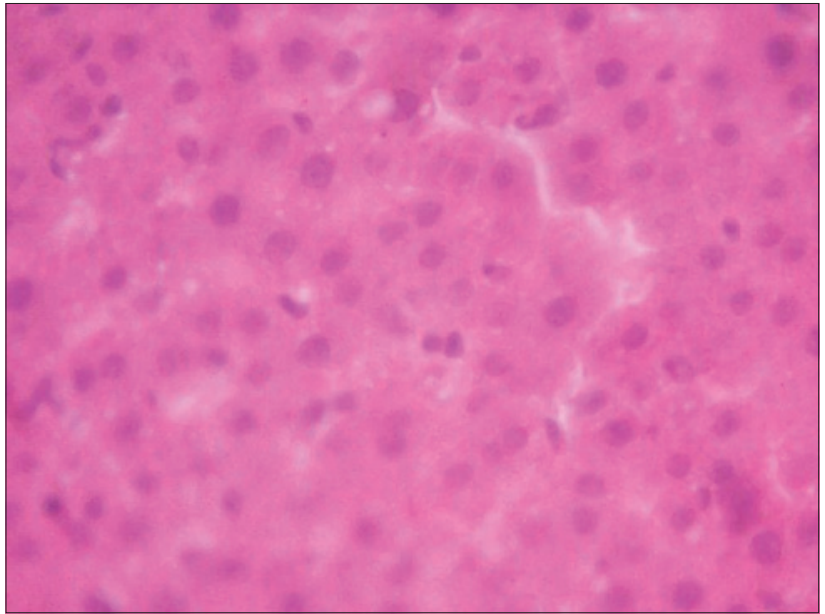

Fig. 4: Group IV: $\mathrm{CCl}_{4}+$ nanospheres RFI $(50 \mathrm{mg} / \mathrm{kg}$ body weight $)$

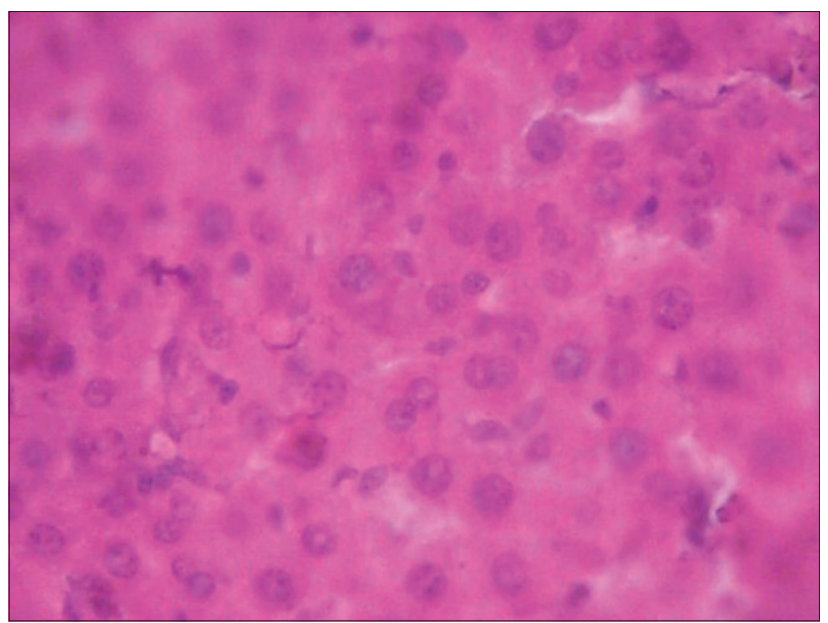

Fig. 5: Group V: $\mathrm{CCl}_{4}$ + nanospheres RFI ( $100 \mathrm{mg} / \mathrm{kg}$ body weight $)$

Groups 4 and 5: These were received C. auriculata polymer nanospheres containing silymarin at a dose fo $50 \mathrm{mg} / \mathrm{kg}$ BW and $100 \mathrm{mg} / \mathrm{kg}$ BW, respectively, for 7 days.

$\mathrm{CCl}_{4} 1 \mathrm{ml} / \mathrm{kg}$ BW was administered intraperitoneally on $7^{\text {th }}$ day $1 \mathrm{hr}$ later after administration of the vehicle, standard and C. auriculata nanospheres, except to Group 1. C. auriculata nanospheres containing silymarin drug was administered per oral, and Tween $80-2 \%$ solution was used as vehicle. The biochemical parameters were determined after $18 \mathrm{hrs}$ of fasting of the last dose.

Daily records of BW of all groups of animals were maintained during the whole experimental period.

\section{Biochemical studies}

After the treatment period, the animals of all groups were anesthetized with anesthetic ether and sacrificed. Blood was collected through the heart puncture.

\section{Non-clinical investigations of a formulation RF1}

The collected blood from the heart puncture was allowed to coagulate for 30 minutes, and serum was separated by centrifugation at $2500 \mathrm{rpm}[8]$. The serum was used to estimate serum glutamate oxaloacetate transaminase (SGOT), serum glutamate pyruvate transaminase, alkaline phosphate, total protein, albumin, globulin, total bilirubin, total cholesterol, and high-density lipoprotein. The liver was isolated weighed, and morphological changes were observed. Reduced glutathione was estimated using DTNB $(0.02 \%$ of 5,5 'dithio (bis) 
nitrobenzoic acid in 1\% trisodium citrate) is also called as Ellman's reagent[9]. The yellow developed was immediately measured at $412 \mathrm{~nm}$. The values were calculated using molar extinction coefficient of chromophore (1.36x $\left.104 \mathrm{~m}^{-1} / \mathrm{cm}\right)$.

\section{Histopathological study}

The liver was transferred to $4 \%$ formalin solution for fixation and later on processed for histopathological studies following the standard procedure described by Raghuramulu et al. (1983). The microtome sections were cut processed and stained with hematoxylin and eosin (Table 2). The section thus obtained was scanned in Carl-Zeiss microscope (Germany) with photographic facility and photomicrographs were taken. Changes present in the different groups in the cytoarchitecture were noticed [10].

We have taken $\times 10$ and $\times 40$ resolutions of liver were taken for all 5 groups of rats.

\section{Relative organ weight (ROW) analysis}

The liver was mopped with filter paper, weighed and the relative weights were calculated and expressed as g/100 g BW (Figures 1-5).

ROW $=$ [absolute organ weight $(\mathrm{g}) /$ body weight of rats on sacrifice day (g) $] \times 100$

\section{Bio-statistical analysis}

All the results were expressed as mean \pm standard error of the mean (Table 4). One way analysis of variance was used for the statistical analysis of data. Dunnett's multiple comparison test was used for determining the significance. A probability value of $p<0.05$ was considered as a significant.

\section{RESULTS AND DISCUSSION}

Liver injuries induced by $\mathrm{CCl}_{4}$ are the best commonly used model for screening of anti-hepatotoxic and/or hepatoprotective activities of drugs. Hepato fibrosis was also investigated extensively. Since the changes associated with $\mathrm{CCl}_{4}$ induced liver damage is similar to that of acute viral hepatitis, hence $\mathrm{CCl}_{4}$ mediated hepatotoxicity was chosen as the experimental model. It has been established that $\mathrm{CCl}_{4}$ is accumulated in hepatic parenchyma cells and metabolically activated by cytochrome p450 - dependent mono-oxygenases to form

Table 3: Hepatotoxicants that will affect the liver injury

\begin{tabular}{|c|c|c|}
\hline Serial number & Drug/hepatotoxicant & Use \\
\hline 1 & Carbon tetrachloride & Toxicant \\
\hline 2 & Acetaminophen & $\begin{array}{l}\text { Analgesic, } \\
\text { antipyretic (NSAIDs) }\end{array}$ \\
\hline 3 & Diclofenac & $\begin{array}{l}\text { Analgesic, } \\
\text { antipyretic (NSAIDs) }\end{array}$ \\
\hline 4 & Sulindac & $\begin{array}{l}\text { Analgesic, } \\
\text { antipyretic (NSAIDs) }\end{array}$ \\
\hline 5 & Celecoxib & COX - 2 inhibitor \\
\hline 6 & Rofecoxib & COX - 2 inhibitor \\
\hline 7 & Nimesulide & COX - 2 inhibitor \\
\hline
\end{tabular}

NSAIDs: Non-steroidal anti-inflammatory drugs a trichloromethyl radical $\left(\mathrm{CCl}_{3}\right)$. The $\mathrm{CCl}_{3}$ radical alkylates cellular proteins and other macromolecules with simultaneous attack on polyunsaturated fatty acids, in the presence of oxygen, to produce lipid peroxides, leading to liver damage. Thus, antioxidant or free radical generation inhibition is important in protection against $\mathrm{CCl}_{4}$ induced liver lesions. Hepatotoxic compounds, such as $\mathrm{CCl}_{4}$, nearly all of the non-steroidal anti-inflammatory drugs (NSAIDs) have been implicated in causing liver injury, which are commonly used for analgesic and antipyretic activities and often used for the relief of non-specific fever (Radwan, 2000), continue to be important for the palliation of pain[11]. Diclofenac and particularly sulindac are reported to be more commonly associated with hepatotoxicity (Bjorkman, 1998). Several NSAIDs have been withdrawn from clinical use because of associated hepatotoxicity (Rabkin et al., 1999). The new more selective COX-2 inhibitors (eg., Celecoxib, rofecoxib, and nimesulide) are also associated with hepatotoxicity (Merlani et al., 2001). Hepatotoxicity from NSAIDs can occur at any time after drug administration, but like most adverse drug reactions most commonly occurs within 6-12 weeks of initiation of therapy (Aithal and Day, 1999). There are two main clinical patterns of hepatotoxicity due to NSAIDs (Rabinovitz and Van Thiel, 1992; Aithal and Day, 1999). The first is acute hepatitis with jaundice, fever, nausea, greatly elevated transaminases and sometimes eosinophilia[12]. The alternative pattern is with serological and histological features of chronic active hepatitis. Some of the NSAIDs which cause liver damage are given in the following Table 3 . Alcohol is one of the causes of hepatic injury due to the accumulation of reactive oxygen species, which in turn causes lipid peroxidation of cellular membranes and proteins and DNA oxidation (Zhou et al., 2002)[13,14].

The above said hepatotoxicants cause marked elevation in serum enzymes and bilirubin levels. It causes a marked decrease in total protein levels. Silymarin is used as standard hepatoprotective compound since it is reported to have a protective effect on the plasma membrane of hepatocytes $[15,16]$. $\mathrm{CCl}_{4}$ has been found to induce extensive liver damage with in a period of $24 \mathrm{hrs}$ following intraperitoneal administration. As a result of this, accumulation of fat in the liver and necrosis in the centrilobular region of the liver occurs. As a consequence, the microsomal enzyme activities are found to decrease and due to lipid peroxidation, the water-soluble enzymes leak into the plasma from the liver. It is shown by the significant decrease in triglycerides and proteins in $\mathrm{CCl}_{4}$ intoxicated rat hepatocytes.

Treatment with C. auriculata nanospheres containing silymarin exhibited significant restoration of the altered biochemical parameters toward normal in $\mathrm{CCl}_{4}$ intoxicated hepatocytes in rats. The effect of $100 \mathrm{mg} / \mathrm{kg}$ body weight $C$. auriculata nanospheres RF1 formulation was found to be better than that of standard silymarin at $25 \mathrm{mg} / \mathrm{kg}$ BW. Acute toxicity studies were performed for the C. auriculata polymer, and it was found safe for the use in nanospheres. The dose of nanospheres was taken at $50 \mathrm{mg} / \mathrm{kg} \mathrm{BW}$ and $100 \mathrm{mg} / \mathrm{kg} \mathrm{BW}$ and standard silymarin at $25 \mathrm{mg} / \mathrm{kg} \mathrm{BW}$, respectively. In vivo hepatoprotective effect at $50 \mathrm{mg} / \mathrm{kg} \mathrm{BW}$ and $100 \mathrm{mg} / \mathrm{kg} \mathrm{BW}$ of C. auriculata nanospheres were significant, with the drug availability for desirable clinical response in animals, comparatively with the pure drug silymarin at $25 \mathrm{mg} / \mathrm{kg} \mathrm{BW}$, positively supported by the histopathology results.

Table 4: Showing results of $\mathrm{CCl}_{4}$ induced hepatotoxicity and treated with Cassia auriculata nanospheres containing silymarin

\begin{tabular}{|c|c|c|c|c|}
\hline Group & $\begin{array}{l}\text { Liver } \\
\text { weight (g) }\end{array}$ & GSH (mg\%) & $\begin{array}{l}\text { Total } \\
\text { protein }(g / d l)\end{array}$ & $\begin{array}{l}\text { Relative organ } \\
\text { weight }(\mathrm{g} / 100 \mathrm{~g} \text { BW.) }\end{array}$ \\
\hline Group I Control & $4.23 \pm 0.24$ & $1.34 \pm 0.02$ & $8.71 \pm 0.80$ & $3.30 \pm 0.17$ \\
\hline Group II Negative $\mathrm{CCl}_{4}$ & $5.63 \pm 0.16$ & $0.50 \pm 0.01$ & $5.20 \pm 1.09$ & $3.69 \pm 0.42$ \\
\hline Group III Standard $(25 \mathrm{mg} / \mathrm{kg} \mathrm{BW})+\mathrm{CCl}_{4}$ & $4.25 \pm 0.13^{* * *}$ & $1.23 \pm 0.01$ & $8.24 \pm 0.20^{* * *}$ & $3.07 \pm 0.29$ \\
\hline Group IV Nanospheres $(50 \mathrm{mg} / \mathrm{kg} \mathrm{BW})+\mathrm{CCl}_{4}$ & $5.13 \pm 0.08$ & $0.70 \pm 0.01$ & $7.53 \pm 0.32$ & $3.41 \pm 0.13^{* * *}$ \\
\hline Group V Nanospheres $(100 \mathrm{mg} / \mathrm{kg} \mathrm{BW})+\mathrm{CCl}_{4}^{4}$ & $4.31 \pm 0.11$ & $1.10 \pm 0.07^{* * *}$ & $7.23 \pm 0.16$ & $3.31 \pm 0.24$ \\
\hline
\end{tabular}

The $\left.\mathrm{P}<0.001,{ }^{* * *} \mathrm{p}<0.001\right)$, ${ }^{* *}$ indicates extremely significant. C. auriculata Cassia auriculata, GHS: Glutathione, BW: Body weight 


\section{CONCLUSION}

In vivo hepatoprotective activity of RF1 formulation of C. auriculata nanospheres containing silymarin has shown significant hepatoprotective and inhibition of oxidative stress results, and we have concluded that it should be sent for further pharmaceutical and pharmacological clinical investigations in human subjects.

\section{REFERENCES}

1. Brahmankar DM, Jaiswal SB. Biopharmaceutics and Pharmacokinetics-A Treatise. $1^{\text {st }}$ ed. New Delhi: Vallabh Prakashan; 1995. p. 296-7.

2. Kingston DG. Modern natural products drug discovery and its relevance to biodiversity conservation. J Nat Prod 2011;74(2):496-511.

3. Jia L, Zhao Y. Current evaluation of the millennium phytomedicine ginseng (I): Etymology, pharmacognosy, phytochemistry, market and regulations. Curr Med Chem 2009;16(19):2475-84.

4. Gunasekaran T, Nigusse T, Dhanaraju MD. Silver nanoparticles as real topical bullets for wound healing. J Am Coll Clin Wound Spec 2012;3(4):82-96.

5. Sahni JK, Baboota S, Ali J. Promising role of nanopharmaceuticals in drug delivery. Pharm Times 2011;43(10):16-8.

6. Qureshi NA, Al-Bedah AM. Mood disorders and complementary and alternative medicine: A literature review. Neuropsychiatr Dis Treat 2013;9:639-58
7. Egert S, Rimbach G. Which sources of flavonoids: Complex diets or dietary supplements? Adv Nutr 2011;2(1):8-14.

8. Jain D, Raturi R, Jain V, Bansal P, Singh R. Recent technologies in pulsatile drug delivery systems. Biomatter 2011;1(1):57-65.

9. Lambert WJ. Considerations in developing a target product profile for parenteral pharmaceutical products. AAPS PharmSciTech 2010;11(3):1476-81.

10. Liong M, Lu J, Kovochich M, Xia T, Ruehm SG, Nel AE, et al. Multifunctional inorganic nanoparticles for imaging, targeting, and drug delivery. ACS Nano 2008;2(5):889-96.

11. Yen FL, Wu TH, Lin LT, Cham TM, Lin CC. Nanoparticles formulation of Cuscuta chinensis prevents acetaminophen-induced hepatotoxicity in rats. Food Chem Toxicol 2008;46(5):1771-7.

12. Boyd EM, Bereczky GM. Liver necrosis from paracetamol. Br J Pharmacol Chemother 1966;26(3):606-14.

13. Dahlin DC, Miwa GT, Lu AY, Nelson SD. N-acetyl-p-benzoquinone imine: A cytochrome P-450-mediated oxidation product of acetaminophen. Proc Natl Acad Sci U S A 1984;81(5):1327-31.

14. Mitchell JR, Jollow DJ, Potter WZ, Gillette JR, Brodie BB. Acetaminophen-induced hepatic necrosis. IV. Protective role of glutathione. J Pharmacol Exp Ther 1973;187(1):211-7.

15. Savides MC, Oehme FW. Acetaminophen and its toxicity. J Appl Toxicol 1983;3(2):96-111.

16. Gupta AK, Misra N. Hepatoprotective activity of aqueous ethanolic extract of chamomile capitula in paracetamol intoxicated albino rats. Am J Pharmacol Toxicol 2006;1(1):17-20. 